\title{
The Effect of Performance-Based Financial Incentives on Improving Health Care Provision in Burundi: A Controlled Cohort Study
}

\author{
Martin Rudasingwa ${ }^{1}$, Robert Soeters ${ }^{2} \&$ Michel Bossuyt $^{3}$ \\ ${ }^{1}$ Institute of Health Economics and Clinical Epidemiology, Faculty of Medicine, University of Cologne, \\ Cologne, Germany \\ ${ }^{2}$ Sina Health, The Hague, Netherlands \\ ${ }^{3}$ Cordaid Burundi, Avenue du Marché No 9, Bujumbura, Burundi \\ Correspondence: Martin Rudasingwa, Institute of Health Economics and Clinical Epidemiology, Faculty of \\ Medicine, University of Cologne, Germany. Tel: 49-221-845-62099. E-mail: martinrudasingwa@gmail.com
}

\author{
Received: August 27, 2014 Accepted: September 28, 2014 Online Published: October 28, 2014 \\ doi:10.5539/gjhs.v7n3p15 URL: http://dx.doi.org/10.5539/gjhs.v7n3p15
}

\begin{abstract}
To strengthen the health care delivery, the Burundian Government in collaboration with international NGOs piloted performance-based financing (PBF) in 2006. The health facilities were assigned - by using a simple matching method - to begin PBF scheme or to continue with the traditional input-based funding. Our objective was to analyse the effect of that PBF scheme on the quality of health services between 2006 and 2008. We conducted the analysis in 16 health facilities with PBF scheme and 13 health facilities without PBF scheme. We analysed the PBF effect by using 58 composite quality indicators of eight health services: Care management, outpatient care, obstetric care, prenatal care, family planning, laboratory services, medicines management and materials management. The differences in quality improvement in the two groups of health facilities were performed applying descriptive statistics, a paired non-parametric Wilcoxon Signed Ranks test and a simple difference-in-differences approach at a significance level of 5\%. We found an improvement of the quality of care in the PBF group and a significant deterioration in the non-PBF group in the same four health services: care management, outpatient care, obstetric care, and prenatal care.

The findings suggest a PBF effect of between 38 and 66 percentage points $(\mathrm{p}<0.001)$ in the quality scores of care management, outpatient care, prenatal care, and obstetric care. We found no PBF effect on clinical support services: laboratory services, medicines management, and material management.

The PBF scheme in Burundi contributed to the improvement of the health services that were strongly under the control of medical personnel (physicians and nurses) in a short time of two years. The clinical support services that did not significantly improved were strongly under the control of laboratory technicians, pharmacists and non-medical personnel.
\end{abstract}

Keywords: Performance-based financing, financial incentive, health quality indicators, quality of health services

\section{Introduction}

In the past several decades, a number of policies have been put into place with the aim of improving the quality of health care. These policies include quality assurance, quality management, patient safety, and evidence-based treatment guidelines. Despite this worthy commitment to improving the health care delivery, there are still many gaps in delivering high-quality care due to many factors, such as non-adherence to standard treatment guidelines, inadequate structure and process measures of quality of care, and lack of appropriate incentives for health care providers (Institute of Medicine 2001).

When health services payment is not based on the quality of care, it may create fewer or no incentives for health care providers to improve the quality of health services (Petersen et al., 2006). In some cases, if providers are not motivated by the payment schemes, this can negatively affect the delivery of health care (Robinson, 2001). Changing the way health care providers are rewarded can create meaningful incentives for quality improvement. For instance, linking payment to performance, health care providers may have an incentive to increase their efforts so that they can improve the quality of care for getting more payments (Canon, 2007; De Brantes, 2006; Rosenthal \& Frank, 2006). In the context of considering the performance of providers in payments, pay for 
performance schemes (P4P) have been implemented in many countries, especially in the United States of America (USA) and the United Kingdom (UK). Performance-based financing programmes have also been implemented first in 1998 in Cambodia (Bhushan et al., 2002) and from the early 2000s in some other developing countries, such as Rwanda, Burundi, the Democratic Republic of Congo, and Cameroon (Soeters, 2014; Canavan et al., 2008)

In the literature performance-based payment uses different terminologies such as "pay-for-performance (P4P)", "Performance-based financing (PBF)", "results-based financing (RBF) “, and "quality-based purchasing (QBP)". The literature shows that in developing countries, those schemes are called performance-based financing (PBF) or results-based financing (RBF), whereas in developed countries, the term of pay-for -performance (P4P) has established itself (Gorter et al., 2013; Fritsche et al., 2014; Eijkenaar et al., 2013). The literature does not describe a standard design for how these schemes should be designed; each scheme defines its own specific goals and the quality components to be improved based on the specific targets of each incentive scheme. This means there is no "one- size- fits- all" design. Thus, the effects of those programmes vary depending on their designs and on the contextual characteristic factors of implementation (Eijkenaar, 2013; Eijkenaar et al., 2013; Mehrotra et al., 2010; Van Herck et al., 2010). Based on different PBF designs in developing countries, the World Bank has recently developed a manual that describes how PBF schemes are designed in practice (Fritsche et al., 2014). As the World Bank is the main financer of PBF schemes in developing countries, the PBF implementers in developing countries tend to follow the World Bank design. The main goals of those programmes are the improvement of structures, processes, outcomes, patient satisfaction, health care management, and the use of technology in health care provision by encouraging providers to adhere more closely to evidence-based standards of care provision (Cannon, 2007; Rosenthal et al., 2007). The health care services are measured using predetermined indicators and providers receive financial incentives based on their performance and outcomes, in which health care specialists hope result in safer, higher quality health care delivery and outcomes, as well as in improving efficiency and reducing health care costs (Cromwell et al., 2011; Canon, 2007; Campbell et al., 2009; Doran et al., 2006; Doran et al., 2008; Doran et al., 2011; Epsein 2004). In some cases, pay- for- performance schemes are combined with public reporting in order to achieve more effect on improving the quality of health care (Lindenauer et al., 2007). The literature suggests that each financial incentives scheme should be designed according to the specific characteristics of the health system settings, to the targeted quality indicators, and to possible unintended effects (Canon 2007; Aron \& Pogach 2006; Rosenthal \& Dudley 2007; Eijkenaar 2013; Witter et al., 2013).

In 2007, the American Institute of Medicine released a report suggesting that health care providers should be rewarded based on their performance and indicating that the experience with P4P programmes was promising and recommended the use of P4P programmes in order to foster the improvements in the quality of health services (Institute of Medicine 2007). Many programmes of performance-based payment have been implemented in the US and early results have shown both a positive and a mixed effect of these performance-based payments in improving the quality of health care (Rosenthal et al., 2007). An 8-year longitudinal pay-for-performance study by Lester et al., (2010) in 35 American medical facilities showed that removing financial incentives from clinical indicators was associated with a decline in the quality of care.

In 2004, the government of the UK, through the National Health Service (NHS), introduced a Pay-for-Performance programme (P4P) for family practitioners called the Quality and Outcomes Framework in order to boost the quality of primary health care. This improvement was to be achieved by measuring and rewarding the delivered quality using 146 quality indicators relating to the management of chronic diseases, organization of care, and patient experience. These quality indicators serve primarily as process indicators (Doran et al., 2008; Roland 2004). The findings revealed that the mean quality scores for aspects of health care that were linked to incentives were higher than those without. However, the authors found that increases in quality of care stopped once providers reached the required quality score (Campbell et al., 2007; Campbell et al., 2009). A study conducted by Doran et al., (2008) showed that the P4P scheme in the UK contributed to a reduction of socio-demographic inequalities in the provision of health care.

In developing countries, the utilization and quality of health services are still very low caused by different factors, such as lack of effective health policies, health care management and organization, non- adherence to treatment guidelines, lack of medical devices and qualified medical personnel, and inappropriate incentives for health providers among many others (Travis et al., 2004; Fryatt et al., 2010). Performance-based payment in health care delivery has been implemented in developing countries with the aim of fostering the improvements of the quality of health care and to address the problem of underutilization of health services in those countries (Soeters, 2014; Musgrove, 2011). 
The early results of PBF schemes in developing countries showed good improvements both in the quality and utilization of health services (Loevinsohn \& Harding, 2005; Canavan et al., 2008; Meessen et al., 2011). The experiences of performance-based payments in Rwanda and the Democratic Republic of Congo, the neighboring countries to Burundi, have shown a positive effect on quality of care. In Rwanda, the quality of health services has improved thanks to the introduction of PBF scheme, especially the services of institutional deliveries and child growth monitoring that were less organized before the PBF scheme (Rusa et al., 2009; Basinga et al., 2011) In the Democratic Republic of Congo, the study of Soeters et al., (2011) revealed that health facilities with PBF scheme provided better quality of care than health facilities without PBF, although the latter health facilities received around five times more external financial assistance than the PBF health facilities. The findings of this study in the Democratic Republic of Congo suggest that more input-based payment may lead to fewer results than well managed less performance-based payment.

However, the evidence of those performance-based payments in improving the quality of health care is mixed and inconclusive, both in developed countries (Bufalino et al., 2006; Doran et al., 2006; Eijkenaar et al., 2013) and in developing countries (Canavan et al., 2008; Gorter et al., 2013). Therefore additional research is needed to evaluate the impact and effectiveness of $\mathrm{P} 4 \mathrm{P}$ programmes.

Burundi is one of the world's poorest countries. The country experienced different civil wars that aggravated its poverty level. Poverty-related infectious diseases are the most causes of morbidity and mortality (World Bank 2011). With the aim of resolving the problems of underprovision, low quality of health care and low motivation of health workers, the Burundian Ministry of Health in collaboration with international NGOs, such as Cordaid and HealthNet TPO, started in 2006 a pilot programme of supply-side performance-based financial incentives in three provinces. This PBF scheme was rolled out nationwide in April 2010. This paper presents the findings of the effect of that PBF scheme in Burundi on the quality of eight health services using quantitative data collected between 2006 and 2008.

\section{Methods}

\subsection{Study Location and Population}

The data were collected in 29 health facilities in 5 health provinces: Bubanza, Cankuzo and Gitega as PBF regions and the provinces of Karuzi and Makamba as non-PBF regions with a total target population of around 2 Millions. These provinces were chosen by the Burundian Ministry of Health based on their similarities in terms of socio-economic and demographic characteristics.

\subsection{Study Design}

The health facilities were assigned at the province level, by using a simple matching method, either to begin the PBF scheme or to continue with the traditional input-based funding. The study design was a prospective experimental study. All the necessary permissions to conduct the study and ethical approvals were obtained.

The quality performance scores of the health facilities were assessed using previously determined health indicators. The performance payment was based on the volume of health services rendered (quantity) and qualitative performance scores (quality). The quality indicators were based on the Burundian national treatment guidelines. The quality of care was assessed every three months by an evaluation team from the district and provincial health authorities in each health facility and at the end a performance score was given, which was taken into consideration for the quality incentive payment. The quantity and quality of health services were verified between 2006 and 2010 by international NGOs that supported the Burundian Government to implement the PBF scheme. From 2010 onwards this role was taken over by a semi-autonomous verification team at provincial level with members from the Burundian health authorities and advised by staff of international NGOs. The PBF incentives represented in average $20 \%$ of the health facilities total revenues (Ministry of Health, 2010).

As an example is shown in the table 1, each quantitative health indicator had a fixed amount of money and the total payment was the product of the number of cases in that indicator and the unit payment of that indicator. The quality health indicators were evaluated and paid quarterly. After the PBF fund holders had paid the PBF incentives to health facilities, the bonuses were distributed to health facility staff using a systematically approach called "indices" instrument. It helped health facility managers to determine the bonus of each health worker in a clear and transparent manner. The indices instrument allowed health facility managers to distribute the bonuses based on the profile and performance criteria of each work staff, such as qualification, experience, years of employment, responsibilities, and worked hours (overtime and not worked hours). The financial incentive from the quality indicators (quality bonus) was calculated as follows: 
Quality incentive $=$ financial incentive from the quantitative indicators received in the three previous months $\times$ $25 \% \times$ overall quality score

At the end of every quarter, the total PBF financial incentives for each PBF health facility were calculated as follows:

Quarterly total PBF payments to health facility $=[$ total quantity payments due $]+[$ total quantity payments due $\times$

$$
25 \% \times \text { overall quality score] }
$$

The Ministry of Health at central level in close collaboration with provincial and district health authorities supervised the whole process of PBF implementation and monitoring. Different workshops, meetings and courses were organized at national and local levels to train relevant PBF stakeholders and to ensure an effective coordination and monitoring by solving in time problems that rose from the PBF implementation.

Table 1. Example of quantitative health indicators and their linked incentives for health centers

\begin{tabular}{|c|c|}
\hline Minimum health package output indicators & $\begin{array}{l}\text { Bonus per } \\
\text { unit in US\$ }\end{array}$ \\
\hline Curative consultancies new case & 0.25 \\
\hline Patient referred and feedback obtained & 1.00 \\
\hline Small surgery intervention & 0.50 \\
\hline Children between 6 and 59 months receiving Vitamin A & 0.05 \\
\hline Child under 1 year completely immunized & 1.50 \\
\hline Pregnant woman fully immunized & 0.50 \\
\hline Mosquito nets distributed & $0.50-2.50$ \\
\hline Patient diagnosed with Tuberculosis (3 sputum checks) & 10.00 \\
\hline TB patient correctly treated during 6 months & 20.00 \\
\hline Latrine newly constructed & 0.70 \\
\hline Family planning: New and Re-attendants: oral \& injectable & 2.00 \\
\hline Family planning: Implant or Intrauterine Devices & 5.00 \\
\hline Family planning: Referral of tubal ligation and vasectomy & 1.00 \\
\hline Antenatal care: new and standard visits & 0.40 \\
\hline Institutional delivery by qualified staff & 2.00 \\
\hline Diagnosis and treatment of Sexually Transmitted Disease & 0.50 \\
\hline Voluntary Counseling and Testing of HIV: Person voluntary counseled and tested for HIV & 1.00 \\
\hline Prevention of HIV Transmission from Mother to Child: Pregnant woman counseled and tested for HIV & 1.00 \\
\hline Prevention of HIV Transmission from Mother to Child: mother treated of HIV before childbirth & 1.00 \\
\hline Prevention of HIV Transmission from Mother to Child: child and mother treated of HIV after childbirth & 1.00 \\
\hline
\end{tabular}

Source: Authors.

\subsection{Study Variables}

In this study, the effect of PBF scheme on the quality of health care delivery in Burundi has been assessed quantitatively by using 58 composite quality indicators in the following eight health care categories: (1) care management, (2) outpatient care, (3) obstetric care, (4) prenatal care, (5) family planning, (6) laboratory services, (7) medicines management, and (8) materials management. The quality indicators consist of structures and process of health care.

The values of the assessed health care services are the mean performance scores of their respective quality indicators. To assess the performance of each health care service, structure and process quality indicators were used. The Table 2 gives an overview of how quality indicators were assessed. 
Table 2. Overview of the quality assessment of health services (58 composite quality indicators)

\begin{tabular}{lll}
\hline Health services & Quality indicators component & Means of assessment \\
\hline Care management & Structure & $\begin{array}{l}\text { Direct observation } \\
\text { Administrative data review }\end{array}$ \\
Obstetric care & Structure & $\begin{array}{l}\text { Direct observation } \\
\text { Medical records review }\end{array}$ \\
& Process & Direct observation \\
Outpatient care & Structure & Medical records review \\
& Process & \\
Prenatal care & Structure & Direct observation \\
& Process & Medical records review \\
Family planning & Structure & Direct observation \\
& Process & Medical records review \\
Laboratory services & Structure & Direct observation \\
& & Documents and records review \\
Medicines management & Structure & Direct observation \\
Materials management & & Documents and records review \\
\hline
\end{tabular}

Source: Authors.

The performance score of each health service is determined by using a checklist of predetermined quality indicators of that health service based on the Burundian treatment guidelines. Each quality indicator was evaluated in point-value by evaluating the composite criteria of this quality indicator. In most cases, all the composite criteria of a quality indicator had to be met for getting all the points. This means that even if one criterion was not met, there were no points for that quality indicator. After checking all the score criteria, a performance quality score (in percentage " 0 to 100 ") was given to each quality indicator. The sum of all performance scores from each health service category gives the total performance score for that health service. The quality (or overall performance) score of each health service is the earned score in all quality indicators divided by the maximum possible score to be earned if the criteria of all quality indicators were met at $100 \%$.

The Table 3 gives a non-detailed list of the quality indicators used in the performance calculation of each health service.

Table 3. Overview of assessed health services and their quality indicators

\begin{tabular}{|c|c|}
\hline Health services & Quality indicators \\
\hline \multirow{8}{*}{$\begin{array}{l}\text { Care } \\
\text { management }\end{array}$} & -Existence of a quarterly and annual business plan showing all operating schedules \\
\hline & -Existence of a clear work schedule of medical personnel \\
\hline & $\begin{array}{l}\text {-Hygiene: cleanliness of rooms and all areas of the availability of disinfectant products, health } \\
\text { facility; }\end{array}$ \\
\hline & -Existence of incinerator \\
\hline & $\begin{array}{l}\text { - Reception of patients: reception rooms with chairs in good state, good organized waiting } \\
\text { system }\end{array}$ \\
\hline & -Communication: availability of a telephone or radio communication \\
\hline & -Fees: the prices of all medical and test services are available and patients have access to them \\
\hline & $\begin{array}{l}\text {-Health geography: existence of a map showing the geography of healthcare provision in the } \\
\text { catchment area }\end{array}$ \\
\hline
\end{tabular}

Obstetric care -The delivery room is in a good state 
-The delivery room is functional

-Episiotomy materials are available

-Episiotomy materials are functional

-Essential instruments and medicines are available

-A partogram is available and used

- The partogram provides an active monitoring of the progress in labour

- The Apgar score is measured and recorded in the partogram

- All deliveries are performed by a qualified medical staff

- The hospitalisation room is appropriate and in a good state

Outpatient care

-Patient's records properly filled out and available

- The availability of all necessary materials and equipment needed for the medical consultation and treatment

- Confidentiality assured: one patient in the consultation room and the door must be closed

- The medical services are consistently provided and available 24 hours a day and 7 days a week

- Treatment of all pathologies in particular malaria, tuberculosis and diarrhea) according to their treatment flowcharts and protocols (to be checked using patient's records)

Prenatal care $\quad$.Patient's registers properly filled out and available

-Case management: high-risk pregnancies are identified and documented and the correct decisions have been made

-Patients (women) get an anti-tetanus vaccine. The vaccine administration must respect the norms: injection into the correct anatomical site of the recipient and correct injection technique. The vaccine storage done according to the norms in the cold chain

Family $\quad$ Yes Availability of contraceptives (oral, injectable, and coil)

planning $\quad$ Medical personnel are able to fix the intrauterine device (IUD contraception)

- Patient's registers properly filled out and available

-Good estimation of the women who use monthly contraceptive method; justification of the recommended, used, and prescribed contraceptives methods

Laboratory -Availability of lab materials and equipment

services $\quad$ Availability of reagents and test strips

Medicines

management

- Availability of all necessary medicines and consumable tracers(to be checked on the list of necessary medicines)

.Pharmacy management (purchasing order, supply, storage, waste removal)

Materials Availability of all necessary materials to be checked on the list of the necessary materials)

management $\quad$.Good management of the material inventor

Source: Authors.

\subsection{Statistical Analysis}

Statistical analysis was performed using SPSS software version 22. Difference in performance scores between 2006 and 2008 were examined using first descriptive statistics and then we subjected the findings of the descriptive analysis to a paired non-parametric Wilcoxon Signed Ranks test with the significance level at alpha $=0.05$. As Greasley (2008) suggests, we cited the exact 2-tailed significance level.

We analyzed first the performance change between 2006 and 2008 in each health category and this was assessed separately in health facilities with and without financial incentives. After we performed a difference-in-differences analysis to assess the effect of the PBF financial incentives on the eight health services quality score, as follows:

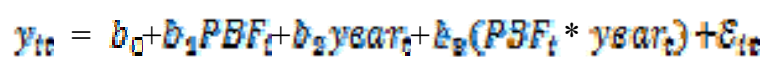

Where $\mathrm{i}$ denotes the health facility and $\mathrm{t}$ is the year (2006 as baseline and 2008 as evaluation year). The dependent variables are the health services quality scores in health facility $i$ in year $t$. PBF is a dummy variable indicating whether the health facility was implementing PBF or not ( 1 for yes and 0 for no). The variable of interest in the interaction term between PBF and year, which shows the net effect of PBF financial incentives 
$\left(b_{a}\right.$ indicates the value of PBF effect). The term $\varepsilon_{i t}$ is the random error. $y_{i t}$ is the quality score of each health service in health facility $i$ and in year (time) $t$.

\section{Results}

\subsection{Study Health Facilities and Population}

Based on the description of the study "location and population" presented in section 2.1, the table 4 presents a summary of the study health facilities and the target population of the intervention and control groups. The intervention and the control areas had approximately the same number of health facilities and population.

Table 4. Health facilities distribution of the study sample in provinces

\begin{tabular}{lccccccc}
\hline Group of health facilities & Bubanza & Cankuzo & Gitega & Karuzi & Makamba & Total & Target population \\
\hline With incentives & 6 & 5 & 5 & 0 & 0 & 16 & 996,279 \\
Without incentives & 0 & 0 & 0 & 7 & 6 & 13 & 889,903 \\
Total & 6 & 5 & 5 & 7 & 6 & 29 & $1,886,182$ \\
\hline
\end{tabular}

Source: Authors.

\subsection{Statistics and Data Analysis of Performance Quality Scores}

We assessed the changes in the quality performance scores between the baseline in 2006 and the first evaluation in 2008, respectively, in 16 health facilities with performance-based financing and in 13 health facilities without such a scheme. The results show an improvement of the mean performance scores from 2006 to 2008 in seven of eight assessed health categories in health facilities with financial incentives. In the health facilities without financial incentives, only one health service registered an improvement in the mean performance scores. The mean performance scores of six of eight assessed health categories decreased, and one health service remained on its baseline score. It is worth noting that the baseline values of performance scores in health facilities with financial incentives were lower than those of the health facilities without financial incentives.

The Wilcoxon signed ranks in the group of health facilities with incentives illustrate that in five health categories a big majority of the 16 health facilities improved their performance scores from 2006 to 2008. These health categories are prenatal care, obstetric care, medicines management, outpatient care, and care management, respectively improved by a number of health facilities in the range of 11 to 15 . For family planning, laboratory services, and materials management, the improvement of their performance scores was achieved in less than half of the 16 health facilities with incentives, respectively in 7, 6, and 7 health facilities. A remarkable deterioration in ranks is only observed in materials management where half of the health facilities registered a decrease of performance score (Table 5).

Table 5. Wilcoxon Signed Ranks in the group of health facilities with incentives ( $\mathrm{n}=16)$

\begin{tabular}{llll}
\hline & Positive ranks & Negative ranks & Ties \\
\hline 2008 care management - 2006 care management & 15 & 1 & 0 \\
2008 Outpatient care-2006 Outpatient care & 14 & 1 & 1 \\
2008 Obstetric care-2006 Obstetric care & 12 & 4 & 0 \\
2008 Family planning-2006 Family Planning & 7 & 3 & 6 \\
2008 Prenatal care-2006 Prenatal care & 11 & 5 & 0 \\
2008 Laboratory services-2006 Laboratory services & 6 & 2 & 8 \\
2008 Medicines Managemen-2006 Medicines Management & 13 & 3 & 0 \\
2008 Materials Management-2006 Materials Management & 7 & 8 & 1 \\
\hline
\end{tabular}

Source: Authors.

In the group of health facilities without incentives, the Wilcoxon signed ranks indicate that in four healthcare categories, a big majority of the health facilities registered a decrease of their performances scores from 2006 to 2008. The performance scores in care management, obstetric care, and prenatal care decreased in 12 of 13 health 
facilities and the performance score of outpatient care decreased in 10 of 13 health facilities. In the other four remaining health categories, namely family planning, materials management, medicines management and laboratory services their performance scores decreased in about half of the 13 health facilities. However, for the medicines management, about half of the 13 health facilities improved their performance scores. For the other health facilities, however, except the care management where there was no performance improvement in any of the health facilities, the performance improvement observed was in less than half of the 13 health facilities (table $6)$.

Our findings from the Wilcoxon statistical test (table 7) indicate significant improvement and deterioration of quality scores over time (post-intervention vs. baseline) in the same four health services respectively in the group of health facilities that received financial incentives and in the group of health facilities that received no financial incentives. Those four health services are care management, outpatient care, prenatal care, and obstetriccare. These results show that the mean performance score in the group of health facilities with incentives after the implementation of the performance-based financing in 2008 was $115 \%$ higher $(p<0.001)$ in the service of care management, $41 \%$ higher $(\mathrm{p}<0.001)$ in the services of outpatient care, $42 \%$ higher $(\mathrm{p}=0.042)$ in the services of prenatal care, and $34 \%$ higher $(\mathrm{p}=0.004)$ in the services of obstetric care than their baseline mean values. In the group of health facilities without incentives, the mean values of performance in these four health services decreased in 2008 respectively $50 \%(p<0.001), 21 \%(p=0.038), 59 \%(p<0.001)$, and $36 \%(p=0.001)$ from the baseline mean values.

Table 6. Wilcoxon Signed Ranks of health care categories performance scores in health facilities without incentives $(\mathrm{n}=13)$

\begin{tabular}{lllc}
\hline & Positive ranks & Negative ranks & Ties \\
\hline 2008 care management-2006 care management & 0 & 12 & 1 \\
2008 Outpatient care-2006 Outpatient care & 3 & 10 & 0 \\
2008 Obstetric care-2006 Obstetric care & 1 & 12 & 0 \\
2008 Family planning-2006 Family Planning & 4 & 7 & 2 \\
2008 Prenatal care-2006 Prenatal care & 1 & 12 & 0 \\
2008 Laboratory services-2006 Laboratory services & 3 & 4 & 6 \\
2008 Medicines Management-2006 Medicines Management & 6 & 5 & 2 \\
2008 Materials Management-2006 Materials Management & 3 & 6 & 4 \\
\hline
\end{tabular}

Source: Authors.

Another clinical service whose quality scores also remarkably improved in health facilities with incentives and decreased in health facilities without incentives, but not significantly, is family planning. The quality performance scores of laboratory test services increased slightly in health facilities with incentives whereas in the health facilities without incentives, the quality score of laboratory test remained at the same value as it was at the baseline in 2006 .

The mean performance scores of medicines management increased both in health facilities with incentives and without incentives, but not significantly. The mean performance score of materials management decreased in both groups, but not significantly.

The findings from the difference-in-differences analysis (table 8) show almost the same results as the Wilcoxon test. A significant increase of between 38 and 66 percentage points $(p<0.001)$ on quality scores is found in services of care management, outpatient care, prenatal care and obstetric care. In addition, the quality score of family planning also increased of 33 percentage points $(\mathrm{p}=0.021)$. The quality scores of laboratory services, medicines management and material management did not statistically change from their baseline quality scores. 
Table 7. Changes of the health services performance quality scores

\begin{tabular}{|c|c|c|c|c|c|}
\hline Health services & $\begin{array}{l}\text { Mean score } \\
2006(\text { SD) }\end{array}$ & $\begin{array}{l}\text { Mean score } \\
2008(\mathrm{SD})\end{array}$ & Difference & $\mathrm{Z}$ value & p-value \\
\hline \multicolumn{6}{|l|}{ Care management } \\
\hline With incentives & $34 \%(16 \%)$ & $73 \%(24 \%)$ & $39 \%$ & -3.391 & 0.000 \\
\hline Without incentives & $48 \%(20 \%)$ & $24 \%(9 \%)$ & $-24 \%$ & -3.061 & 0.000 \\
\hline Difference & $-14 \%$ & $49 \%$ & $63 \%$ & & \\
\hline \multicolumn{6}{|l|}{ Outpatient care } \\
\hline With incentives & $56 \%(22 \%)$ & $79 \%(19 \%)$ & $23 \%$ & -3.184 & 0.000 \\
\hline Without incentives & $73 \%(17 \%)$ & $58 \%(19 \%)$ & $-15 \%$ & -2.062 & 0.038 \\
\hline Difference & $-17 \%$ & $21 \%$ & $38 \%$ & & \\
\hline \multicolumn{6}{|l|}{ Prenatal care } \\
\hline With incentives & $45 \%(23 \%)$ & $64 \%(35 \%)$ & $19 \%$ & -2.019 & 0.042 \\
\hline Without incentives & $80 \%(20 \%)$ & $33 \%(18 \%)$ & $-47 \%$ & -3.115 & 0.000 \\
\hline Difference & $-35 \%$ & $31 \%$ & $66 \%$ & & \\
\hline \multicolumn{6}{|l|}{ Obstetric care } \\
\hline With incentives & $56 \%(16 \%)$ & $75 \%(19 \%)$ & $19 \%$ & -2.744 & 0.004 \\
\hline Without incentives & $74 \%(18 \%)$ & $47 \%(22 \%)$ & $-27 \%$ & -3.077 & 0.001 \\
\hline Difference & $-18 \%$ & $28 \%$ & $46 \%$ & & \\
\hline \multicolumn{6}{|l|}{ Family planning } \\
\hline With incentives & $35 \%(29 \%)$ & $52 \%(43 \%)$ & $17 \%$ & -1.785 & 0.080 \\
\hline Without incentives & $35 \%(32 \%)$ & $19 \%(19 \%)$ & $-16 \%$ & -1.386 & 0.185 \\
\hline Difference & $0 \%$ & $33 \%$ & $33 \%$ & & \\
\hline \multicolumn{6}{|l|}{ Laboratory services } \\
\hline With incentives & $72 \%(38 \%)$ & $81 \%(19 \%)$ & $9 \%$ & -1.207 & 0.242 \\
\hline Without incentives & $60 \%(40 \%)$ & $60 \%(40 \%)$ & $0 \%$ & -0.085 & 1.000 \\
\hline Difference & $12 \%$ & $21 \%$ & $9 \%$ & & \\
\hline \multicolumn{6}{|c|}{ Medicines management } \\
\hline With incentives & $67 \%(19 \%)$ & $82 \%(18 \%)$ & $15 \%$ & -1.662 & 0.101 \\
\hline Without incentives & $58 \%(25 \%)$ & $65 \%(13 \%)$ & $7 \%$ & -0.406 & 0.727 \\
\hline Difference & $9 \%$ & $17 \%$ & $8 \%$ & & \\
\hline \multicolumn{6}{|l|}{ Materials management } \\
\hline With incentives & $73 \%(27 \%)$ & $59 \%(41 \%)$ & $-14 \%$ & -0.942 & 0.363 \\
\hline Without incentives & $64 \%(34 \%)$ & $61 \%(38 \%)$ & $-3 \%$ & -0.774 & 0.484 \\
\hline Difference & $-9 \%$ & $-2 \%$ & $-11 \%$ & & \\
\hline
\end{tabular}

Source: Authors.

Note. (SD): standard deviation. 
Table 8. Difference in performance quality scores between PBF and non-PBF facilities from the difference-in-difference regression analysis

\begin{tabular}{llll}
\hline Health services & $\begin{array}{l}\text { Difference of difference* in } \\
\text { improvement rates }\end{array}$ & Coefficients $(95 \% \mathrm{CI})$ & P-value \\
\hline Care management & $63 \%$ & $0.627(0.548$ to 0.706$)$ & 0.000 \\
Outpatient care & $38 \%$ & $0.381(0.293$ to 0.469$)$ & 0.000 \\
Obstetric care & $46 \%$ & $0.456(0.372$ to 0.54$)$ & 0.000 \\
Prenatal care & $66 \%$ & $0.669(0.553)$ to 0.785$)$ & 0.000 \\
Family planning & $33 \%$ & $0.328(0.196$ to 0.462$)$ & 0.021 \\
Laboratory services & $9 \%$ & $0.088(-0.053$ to 0.229$)$ & 0.539 \\
Medicines management & $8 \%$ & $0.075(-0.037$ to 0.187$)$ & 0.511 \\
Material management & $-11 \%$ & $-0.114(-0.311$ to 0.083$)$ & 0.566 \\
\hline
\end{tabular}

Source: Authors.

Notes: $*$ The difference of difference $=($ mean score 2008 PBF - mean score 2006 PBF $)$ - (mean score 2008 non-PBF - mean score 2006 non-PBF). CI: Confidence Interval. CI and P-values were calculated using bootstrapping method (1000 bootstrap samples).

\section{Discussion}

The findings of our assessment of the effect of PBF scheme on health care provision in Burundi suggest an improvement of the performance quality scores of care management and of four clinical health services: outpatient care, prenatal care, and obstetriccare. But the PBF had no effect on the following three clinical support services: laboratory services, medicines management and materials management. Our findings are consistent with PBF evaluations in other countries, such as a study done in Democratic Republic of Congo (Soeters et al., 2011) and three controlled studies done in Haiti (Eichler et al., 2007; Eichler et al., 2009; Zeng et al., 2013), where the authors suggested that the performance-based financial incentives contributed to an improvement in both the quality and quantity of some health services. As noted elsewhere, an international review of the literature about financial incentives in developing countries demonstrated that these incentives contributed to improvement in both the quality of health care and the utilization of health services (Canavan et al., 2008).

The findings of our study show that the mean performance scores of seven of eight analysed health categories in health settings with performance-based financing increased, with a great significant improvement in care management, outpatient care, obstetric services, and prenatal care. On the other hand, in health facilities without financial incentives, there is no health category that significantly improved. Excluding the mean performance scores in laboratory services, which remained at their baseline values in 2008 and the mean performance score of medicines management that slightly increased, in health settings without financial incentives, the performance scores of the other six of eight assessed health categories deteriorated. A remarkable deterioration was observed in four health categories: care management, outpatient care, obstetric services, and prenatal care. These findings indicate that the improvement and deterioration in the quality scores is not the same for all health services. As mentioned previously, we found a great improvement in quality scores in health settings that received financial incentives and a great deterioration of quality scores in health settings without financial incentives in the same four health services.

These health services that improved have to do with health care organization and clinical services and are the pillar services in health care provision, and were during this PBF pilot strongly under the control of medical personnel (physicians and nurses). The health care categories that neither significantly improved nor significantly deteriorated are clinical support services and were strongly under the control of laboratory technicians, pharmacists and non-medical personnel. The improvement of care management and clinical services can be attributed to the incentives payment. The PBF scheme was designed in a way the health providers knew that they would be evaluated and that the obtained quality performance scores were very crucial in the calculation of the quality bonus. This led to increased provider efforts. Another possible explanation is that the used balanced scorecard (quality indicator checklist) to evaluate the performance scores helped the providers to improve medical records filing and to know what services they should improve and how (PBF as 
feedback-instrument). But this evaluation tool was used in both health facilities with financial incentives and without; we would then expect to see a same change of quality performance scores in both groups of health facilities.

A controlled study on performance-based financing in Rwanda, a neighbouring country of Burundi, concluded that the quality of prenatal care and preventive care for children that had large financial incentives, registered significant improvement and that in general the quality improvement was observed for the health services with high incentives (Basinga et al., 2011). The non-variation in quality scores of clinical support services can be attributed to the routine operations and to lack of knowledge and skills how to improve them. By upgrading the management and organizational skills of clinical support services, the effects of the PBF scheme on those services would be further enhanced.

These findings highlight the fact that performance-based financial incentive schemes do not have the same effect on the improvement of the quality of health services; this effect may vary depending on incentivized health services, incentive programme design, and specific characteristics of health settings among others. This information suggests that the targeted goals of a performance-based financing programme are important and that the programme should be well-designed in order to achieve good quality performance scores. The evidence also reveals that before implementing a programme of performance-based financing, it should be well-analysed and, if needed, pre-tested with a comprehensive pilot project in order to assess whether the programme will lead to positive results. The literature gives some reasons why some quality indicators improve and others not: large enough incentives, different incentives among quality indicators, indicators that are more influenceable to improve, the quality scores at the baseline, and the incentive quality thresholds (Schatz 2008; Rosenthal et al., 2005; Basinga et al., 2011).In addition, providers may put a lot of effort into improving the incentivized health services and neglect the non-incetivized ones. Doran et al., (2011) pointed out that health providers in the UK (financial incentive scheme) put less attention on health services that were not rewarded under the financial incentive programme. The mixed effects of performance-based incentives are supported by a systematic review of performance-based payment programmes in health care conducted by Petersen et al. (2006), in which the authors found that 13 out of 17 reviewed studies showed a positive effect on quality improvement, 2 studies showed, respectively, mixed effect and non-effect on the quality of care Furthermore, a study of Kahn et al., (2006) done in the USA indicated that the effect of pay-for-performance schemes was different among hospitals and health conditions. The existing evidence suggests that performance-based financial incentives may bolster the quality improvement in developing countries more than in developed countries (i.e., the UK and the US). This is based on the fact that in developing countries the quality of care is very low; for example, the process of care is not respected and health providers do not fully adhere to clinical practice guidelines. As the study of Rosenthal et al., (2005) suggests, financial incentives lead more to quality improvement in health facilities with lower quality than health facilities with higher quality at the baseline. For more clarity about the different effects of financial incentives on the quality of care in developed and developing countries, robust systematic reviews on this issue are needed and should be the subject of further research.

Our study has several possible limitations. First, our sample of 29 health facilities seems to be small and this may result in a higher probability of Type II error and the lack of statistical significance for some health services. However, our findings shed light on the potential effect of financial incentives on improving health care provision in a very low-income country of Burundi. Second, from our findings we cannot clearly explain why the performance scores of some health services did not improve or why the performance scores of some health services deteriorated, mainly in health facilities without incentives. Third, our analysis was limited to some health services with available data. Finally, the used quality indicators focus mostly on structure and process quality indicators. We did not perform any analysis of the PBF incentives on health outcomes due to lack of appropriate data. However, PBF schemes are beeing widely implemented in developing countries (Honda, 2013) and our findings demonstrate that financial incentives can help to improve the structure and process quality indicators in a developing country with hope that the health outcomes will also improve.

\section{Conclusion}

The findings of our study suggest, all other factors being equal, that PBF financial incentives in Burundi had an effect on improving the quality of health services that were under the control of medical personnel. Since in a performance-based payment scheme a higher performance score means more money, health providers might have been motivated by this incentive to improving their way of delivering health services by respecting the treatment guidelines and other care-related specifications prescribed in the incentives scheme. The incentive scheme may have had a positive effect on the treatment of patients since the programme is designed in a way patients should get the right health services at the right time and in the right manner according to the Burundian 
national treatment guidelines, but this is not the subject of our paper and should be analysed in further research. This study provides evidence that performance-based financial incentives that are appropriately designed might have the potential to contribute to a significant improvement in health services performance, especially in developing countries like Burundi, where the quality of care is still at a low level. However, the findings indicate that PBF scheme cannot stimulate the improvement of health care quality at the same level because under PBF scheme quality indicators improve differently or some quality indicators do not improve. This suggests that the PBF effect is context-based in terms of health services and health settings. Further research is still needed to well understand the PBF interaction with other factors that influence the improvement of health care delivery such as different provider payment mechanisms (fee-for-service, capitation, flat rate per case or per day, etc.). More research is needed on how to make PBF interventions as comprehensive as possible to avoid the pitfalls of vertical (stand-alone) programmes and to reduce socio-demographic inequalities in care provision. Future assessments should as well include the long-term sustainability of incentives programmes and what would happen to health care performance once those incentives are removed because of lack of funds or support; this would help decision makers to attribute to PBF incentives the effect it deserves in health care provision.

The implementers of PBF schemes should design their programmes in a way they can avoid potentially unintended consequences of financial incentives such as the neglect of health services that are not included in the incentives programme. With the aim of improving the health care quality in developing countries in general, and in Burundi in particular, it seems that performance-based financial incentives will play an important role in the future. Although the results of our research are based on some quality indicators of some health services and on a relatively small sample of health facilities, the results from this experience of financial incentives are extremely relevant for policy making.

\section{Acknowledgements}

We thank the Cordaid Netherlands for funding the data collection and for making available the data set for this study, the Burundian Ministry of Health for their kind collaboration. We also thank the Institute of Health Economics and Clinical Epidemiology of the University of Cologne in Germany for useful comments on the study design and on the early drafts.

\section{References}

Aron, D., \& Pogach, L. (2006). Specialists versus generalists in the era of Pay for Performance: "A plague o" both your houses! Qual Saf Health Care, 16, 3-5. http://dx.doi.org/10.1136/qshc.2006.021006

Basinga, P., Gertler, P. J., Binagwaho, A., Soucat, A. L. B., Sturdy, J., \& Vermeersch, C. M. J. (2013). Effect on maternal and child health services in Rwanda of payment to primary healthcare providers for performance: an impact evaluation. Lancet, 377, 1421-1428. http://dx.doi.org/10.1016/S0140-6736(11)60177-3

Bhushan, I., Keller, S., \& Schwartz, B. (2002). "Achieving the Twin Objectives of Effi ciency and Equity: Contracting Health Services in Cambodia." ERD Policy Brief No. 6, Asian Development Bank, Manila. Retrieved April 15, 2014 from http://www.adb.org/publications/achieving-twin-objectives-efficiencyand-equity-contracting-healthmservices-cambodia

Bufalino, V., Peterson, E. D., Burke, G. L., LaBresh, K. A., Jones, D. W., Faxon, D. P., ... Krumholz, H. M. (2006). Payment for Quality: Guiding Principles and Recommendations. Principles and Recommendations from the American Heart Association's Reimbursement, Coverage, and Access Policy Development Workgroup. Circulation, 113, 1151. http://dx.doi.org/10.1161/CIRCULATIONAHA.105.171760

Busogoro, J. F., \& Beith, A. (2010). Pay for performance for improved health in Burundi. Bethesda, Maryland, Health System 20/20 project, Ab. Associates Inc. Retrieved February 10, 2014, from http://www.rbfhealth.org/library/doc/371/pay-performance-improved-health-burundi

Campbell, S., Reeves, D., Kontopantelis, E., Middleton, E., Sibbald, B., \& Roland, M. (2007). Quality of primary care in England with the introduction of pay for performance. $N$ Eng $J$ Med, 357, 181-190. http://dx.doi.org/10.1056/NEJMsr065990

Campbell, S. M., Reeves, D., Kontopantelis, E., Sibbald, B., \& Roland, M. (2009). Effects of pay for performance on the quality of primary care in England. $N$ Eng $J$ Med, 361, 368-378. http://dx.doi.org/10.1056/NEJMsa0807651

Canavan, A., Toonen, J., \& Elovaino, R. (2008). Performance Based Financing. An international review of the literature, KIT Development policy and practice, Amsterdam. Retrieved February 14, 2014, from https://www.kit.nl/net/KIT_Publicaties_output/ShowFile2.aspx?e=1533 
Cannon, M. F. (2007). Pay -for- Performance: Is Medicare a Good Candidate? Yale Journal of Health Policy, Law, and Ethics, 7(1), Article1. Retrieved January 31, 2014, from http://digitalcommons.law.yale.edu/yjhple/vol7/iss1/1

Cromwell, J., Trisolini, M. G., Pope, G.C., Michell, J. B., \& Greenwald, L. M. (2011). Pay for performance in Healthcare: Methods and Approaches. RTI Press Publication. NO. BK- 002-1103. Retrieved February 15, 2014, from http://www.rti.org/pubs/bk-0002-1103-mitchell.pdf

De Brantes, F. (2006). Pay for Performance and beyond. A Recipe for improving Healthcare, in the Quality Conundrum: practical approaches for enhancing patient care (pp. 110-114). Retrieved March 11, 2014, from http://www.bridgestoexcellence.org/assets/Documents/P4PandBeyondarticlebyFSB.pdf

Doran, T., Kontopantelis, E., Valderas, J. M., Campbell, S., Roland, M., Salisbury, C., \& Reeves, D. (2011). Effect of financial incentives on incentivised and non-incentivised clinical activities: longitudinal analysis of data from UK Quality and Outcomes Framework. BMJ, 342, d3590. http://dx.doi.org/10.1136/bmj.d3590

Doran, T., Fullwood, C., Kontopantelis, E., \& Reeves, D. (2008). Effect of financial incentives on inequalities in the delivery of primary clinical care in England: analysis of clinical activity indicators for the quality and outcomes framework. The Lancet, 372, 728-736. http://dx.doi.org/10.1016/S0140-6736(08)61123-X

Doran, T., Fullword, C., Gravelle, H., Reeves, D., Kontopantelis, E., Hiroeh, U., \& Roland, M. (2006). Pay-forPerformance programs in family practices in the United Kingdoms. $N$ Eng $J$ Med, 355, 375-384. http://dx.doi.org/10.1056/NEJMsa055505

Eichler, R., Auxila, P., Antoine, U., \& Desmangles, B. (2007). Performance-Based Incentives for health: Six years of Results from supply- side programs in Haiti. Washington, DC: Center for Global Development.

Eichler, R., Auxila, P., Antoine, U., \& Desmangles, B. (2009). Haiti:Going to Scale with a Performance Incentive Model. Washington, DC: Center for Global Development.

Eijkenaar, F. (2013). Key Issues in the Design of Pay for Performance Programs. European Journal of Health Economics, 14, 117-131. http://dx.doi.org/10.1007/s10198-011-0347-6

Eijkenaar, F., Emmert, M., Scheppach, M., \& Schöffski, O. (2013). Effects of pay-for-performance in health care: a systematic review of systematic reviews. Health Policy, 10, 115-130. http://dx.doi.org/10.1016/j.healthpol.2013.01.008

Epstein, A. M. (2006). Pay for performance in the United States and Abroad. New England Journal of Medicine, 355, 406-408. http://dx.doi.org/10.1056/NEJMe068131

Fritsche, G. B., Soeters, R., \& Meessen, B. (2014). Performance-Based Financing. Toolkit. The World Bank, Washington DC. http://dx.doi.org/10.1596/978-1-4648-0128-0

Fryatt, R., Mills, A., \& Nordstrom, A. (2010). Financing of health systems to achieve the health Millennium Development Goals in low-income countries. Lancet, 375, 419-426. http://dx.doi.org/10.1016/S01406736(09)61833-X

Gorter, A.C., Ir, P., \& Meessen, B. (2013). Evidence Review, Results-Based Financing of Maternal and Newborn Health Care in Low- and Lower- middle-Income Countries, study commissioned and funded by the German Federal Ministry for Economic Cooperation and Development (BMZ) through the sector project PROFILE at GIZ - German Society for International Cooperation.

Greasley, P. (2008). Quantitative Data Analysis Using SPSS. An Introduction for Health \& Social Science. Maidenhead: Open University Press.

Honda, A. (2013). 10 best resources on ... pay for performance in low- and middle-income countries. Health policy and planning, 28, 454-457. http://dx.doi.org/10.1093/heapol/czs078

Institute of Medicine. (2007). Pathways to Quality Health Care: Rewarding Provider Performance - Aligning Incentives in Medicare. Washington, DC: The National Academies Press.

Institute of Medicine. 2001. Crossing the quality chasm: a new health system for the 21 st centure. Washington, DC: National Academies Press.

Kahn III, C. N., Ault, T., Isenstein, H., Potetz, L., \& Van Gelder, S. (2006). Snapshot of Hospital Quality Reporting And Pay-For-Performance under Medicare, Health Affairs, 25, 148-162. http://dx.doi.org/10.1377/hlthaff.25.1.148 
Lester, H., Schmittdiel, J., \& Selby J et al., ( 2010). The impact of removing financial incentives from clinical quality indicators: longitudinal analysis of four Kaiser Permanente indicators. BMJ, 340, c1898. http://dx.doi.org/10.1136/bmj.c1898

Lindenauer, P.K., Remus, D, Roman, S., Rothberg, M. B., Benjamin, E. M., Ma, A., \& Bratzler, D. W. (2007). Public Reporting and Pay for Performance in Hospital Quality Improvement. $N$ Eng $J$ Med, 356, 486-496. http://dx.doi.org/10.1056/NEJMsa064964

Loevinsohn, B., \& Harding, A. (2005). Buying results? Contracting for health service delivery in developing ountries, The Lancet, 366, 676- 681. http://dx.doi.org/10.1016/S0140-6736(05)67140-1

Mehrotra, A., Sorbero, M. E., \& Damberg, C. L. (2010). Using the lessons of behavioral economics to design more effective pay-for-performance programs. Am. J. Manag. Care, 16, 497-503.

Meessen, B., Soucat, A., \& Sekabaraga, C. (2011). Performance-based financing: just a donor fad or a catalyst towards comprehensive health-care reform? Bulletin of the World Health Organization, 89, 153156. http://dx.doi.org/10.2471/BLT.10.077339

Ministry of Health. (2010). Manuel de procédures pour la mise en œuvre du financement basé sur la performance au Burundi. Version originale Bujumbura.

Musgrove, P. (2011). Financial and other rewards for good performance or results: a guided tour of concepts and terms and a short glossary. Results-Based Financing for Health. The World Bank, Washington DC. Retrieved January 24, 2014, from http://www.rbfhealth.org/system/files/RBFglossarylongrevised.pdf

Petersen, L. A., Woodard, L. D., Urech, T., Daw ,C., \& Sookanan, S. (2006). Does Pay for Performance improve the quality of Healthcare? Ann. Intern. Med., 145, 265-272. http://dx.doi.org/10.7326/0003-4819-145-4-200608150-00006

Roland, M. (2004). Linking physicians'pay to quality of care - a major experiment in the United Kingdom. $N$ Engl J Med, 351, 14448- 14454. http://dx.doi.org/10.1056/NEJMhpr041294

Rosenthal, M. B, Frank, R. G., Li, Z., \& Epstein, A. M. (2005). Early Experience with Pay-for- Performance: From Concept to Practice. JAMA, 294, 1788-1793. http://dx.doi.org/10.1001/jama.294.14.1788

Rosenthal, M. B., Frank, R. G. (2006). What Is the Empirical Basic for Paying for Quality in Health Care? Med Care Res Rev, 63, 135. http://dx.doi.org/10.1177/1077558705285291

Rosenthal, M. B., Dudley, A. R. (2007). Pay-for-Performance: Will the Latest Payment Trend improve Care? JAMA, 297, 740-744. http://dx.doi.org/10.1001/jama.297.7.740

Rosenthal, M. B., London, B., Howitt, K., Song, H. R., Epstein, A. M. (2007). Marketwatch. Climbing up the pay - for- performance Learning curve: Where Are The Early Adopters Now? In: Health Affairs, 26, 1674-1682. http://dx.doi.org/10.1377/hlthaff.26.6.1674

Robinson, J.C. (2001). Theory and practice in the design of physician payment incentives. Journal of public health and health care policy, 79, 149-177. http://dx.doi.org/10.1111/1468-0009.00202

Rusa, L., Ngirabega, J.D., Janssen, W., Van Bastelaere, S., Porignon, D., \& Vandenbulcke, W. (2009). Performance - based financing for better quality of services in Rwandan health centers: 3- year experience. Tropical Medicine and International Health, 14, 830-837. http://dx.doi.org/10.1111/j.1365-3156.2009.02292.x

Schatz, M. (2008). Does pay-for-performance influence the quality of care? Current Opinion in Allergy and Clinical Immunology, 8, 21321. http://dx.doi.org/10.1097/ACI.0b013e3282fe9d1a

Soeters, R. (Ed.). (2014). PBF in Action. Theory and Instruments. PBF Course Guide. The Hague: CordaidSINA Health. $\quad$ Retrieved April 30, 2014, from http://www.sina-health.com/wp-content/uploads/PPFCourseBookCordaid-SINA-TheoryActionEng-V300314 .pdf

Soeters, R., Peerenboom, P., Mushagalusa, P., \& Kimanuka, C. (2011). Performance-Based Financing Experiment Improved Health Care In The Democratic Republic of Congo. Health Affairs, 30, 1518-1527. http://dx.doi.org/10.1377/hlthaff.2009.0019

Travis, P., Bennett, S., Haines, A., Pang, T., Bhutta, Z., Hyder, A. A., ...Evans, T. (2004). Overcoming health systems constraints to achieve the Millennium Development Goals. Lancet, 364, 900-906. http://dx.doi.org/10.1016/S0140-6736(04)16987-0 
Van Herck, P., De Smedt, D., Annemans, L., Remmen, R., Rosenthal, M. B., \& Sermeus, W. (2010). Systematic review: effects, design choices, and context of pay-for-performance in health care. BMC Health Services Research, 10, 247. http://dx.doi.org/10.1186/1472-6963-10-247

Witter, S., Toonen, J., Meessen, B., Kagubare, J., Fritsche, G., \& Vaughan, K. (2013). Performance-based financing as health system reform: mapping the key dimensions for monitoring and evaluation. $B M C$ Health Services Research, 13, 367. http://dx.doi.org/10.1186/1472-6963-13-367

World Bank. (2011). Africa Development Indicators. Retrieved May 20, 2014, from http://data.worldbank.org/sites/default/files/adi_2011-web.pdf

Zeng, W., Cros, M.,Wright, K. D., \& Shepard, D.S. (2013). Impact of performance-based financing on primary health care in Haiti. Health policy and planning, 28, 596-605. http://dx.doi.org/10.1093/heapol/czs099

\section{Copyrights}

Copyright for this article is retained by the author(s), with first publication rights granted to the journal.

This is an open-access article distributed under the terms and conditions of the Creative Commons Attribution license (http://creativecommons.org/licenses/by/3.0/). 